\title{
Vitrification and New Phases in the Water:Pyrimidine Binary Eutectic Systems
}

\section{Supporting Information}

Ewa Patyk-Kaźmierczak, ${ }^{\mathrm{a}}$ Marcin Podsiadło, ${ }^{\mathrm{a}}$ Marek Szafrański, ${ }^{\mathrm{b}}$ Andrzej Katrusiak ${ }^{\mathrm{a}}$

${ }^{a}$ Department of Materials Chemistry, Faculty of Chemistry, Adam Mickiewicz University, Umultowska 89b, 61614 Poznań, Poland; ' Faculty of Physics, Adam Mickiewicz University, Umultowska 85, 61-614 Poznań, Poland

\section{Table of content}

Pictures of Samples Used for PXRD experiments

Differential Scanning Calorimetry Thermographs..... 5

Powder X-Ray Diffraction Patterns 8 


\section{Pictures of Samples Used for PXRD experiments}

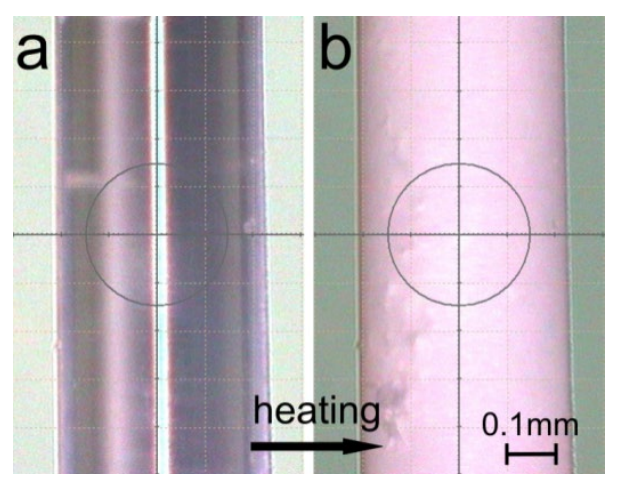

Figure S1. Vitrified water:pyrimidine binary mixture (4:1 molar ratio) after shock cooling at $150 \mathrm{~K}(\mathrm{a})$, and a powder sample at $182 \mathrm{~K}$, obtained after heating the vitreous state (b).
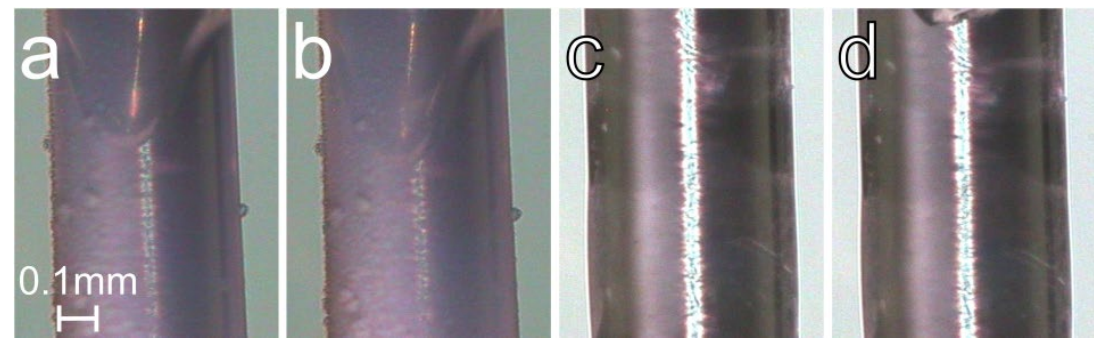

Figure S2. Two different capillaries filled with shock cooled water:pyrimidine binary mixture $(4: 1$ molar ratio) at $140 \mathrm{~K}$, before $(a, c)$ and after $(b, d)$ PXRD experiments. In case of the first capillary $(a, b)$ PXRD pattern showed formation of pure vitreous state, while in case of second $(c, d)$ some diffraction peaks were visible as well, besides otherwise amorphous pattern.

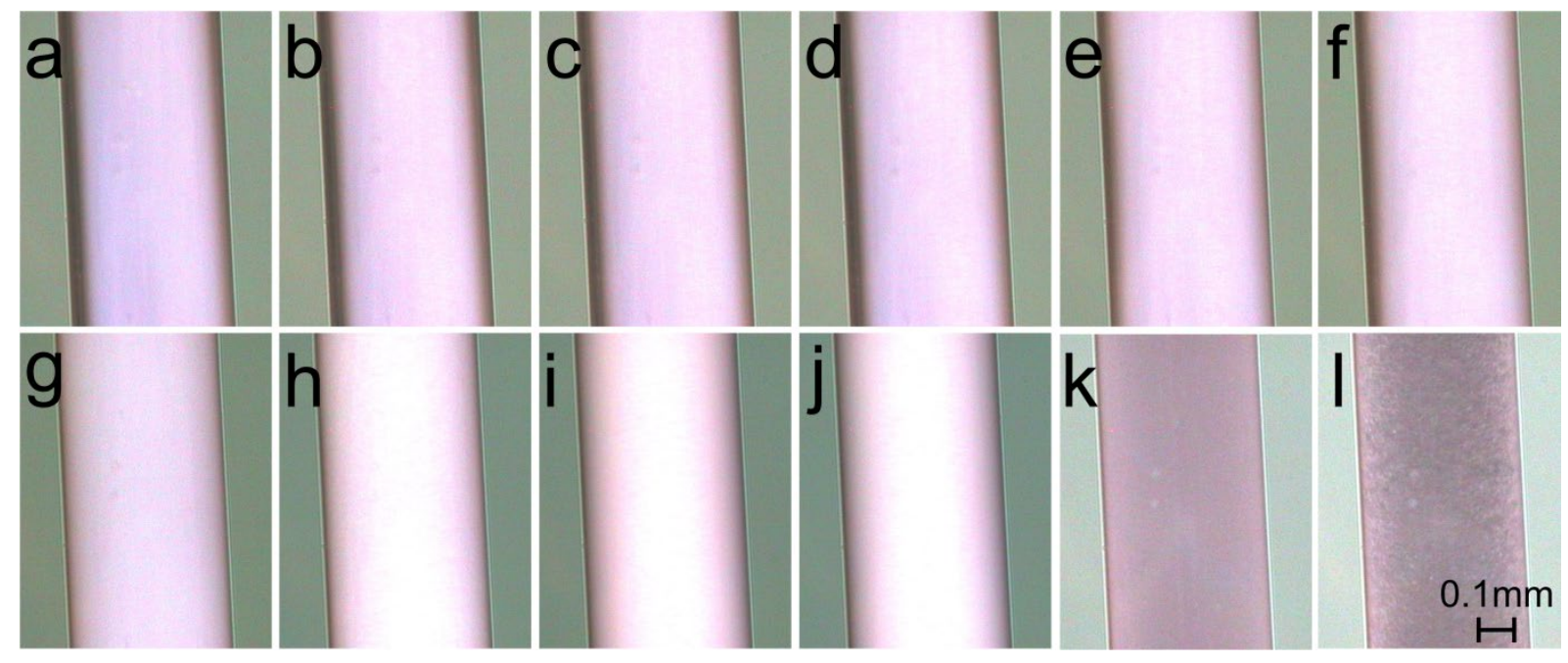

Figure S3. Capillary filled with water:pyrimidine binary mixture (4:1 molar ratio) before and after PXRD experiments, respectively, at $150(\mathrm{a}, \mathrm{b}), 165(\mathrm{c}, \mathrm{d}), 182(\mathrm{e}, \mathrm{f}), 210(\mathrm{~g}, \mathrm{~h}), 222(\mathrm{i}, \mathrm{j})$ and $230 \mathrm{~K}(\mathrm{k}, \mathrm{l})$. Cooling and heating of the sample was carried out using a $2.5 \mathrm{~K} \cdot \mathrm{min}^{-1}$ rate. 


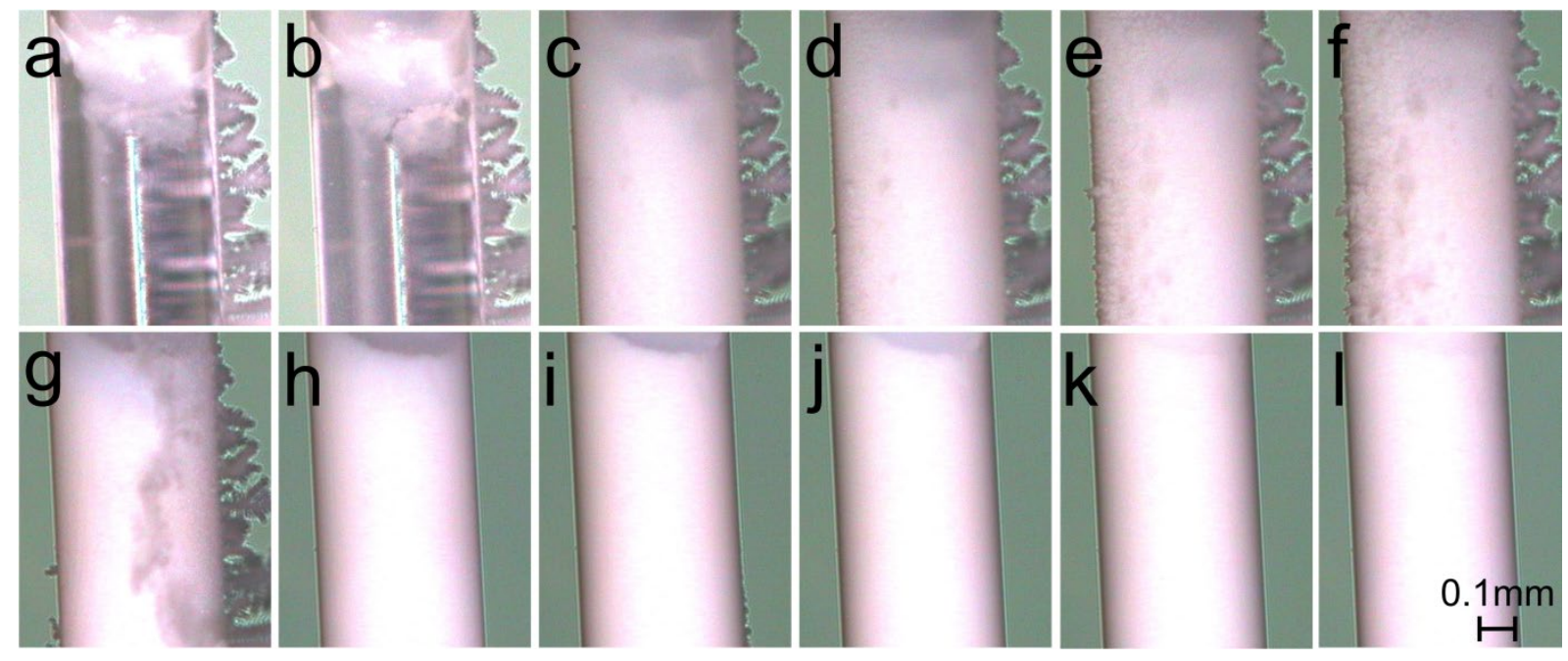

Figure S4. Capillary filled with water:pyrimidine binary mixture (4:1 molar ratio) before and after PXRD experiments, respectively, at $150(\mathrm{a}, \mathrm{b}), 165(\mathrm{c}, \mathrm{d}), 182(\mathrm{e}, \mathrm{f}), 210(\mathrm{~g}, \mathrm{~h}), 222(\mathrm{i}, \mathrm{j})$ and $230 \mathrm{~K}(\mathrm{k}, \mathrm{l})$. Cooling and heating of the sample was carried out using a $3 \mathrm{~K} \cdot \mathrm{min}^{-1}$ rate. Icing of the sample visible in figures a-g is due to the high humidity and use of a fast nitrogen flow.

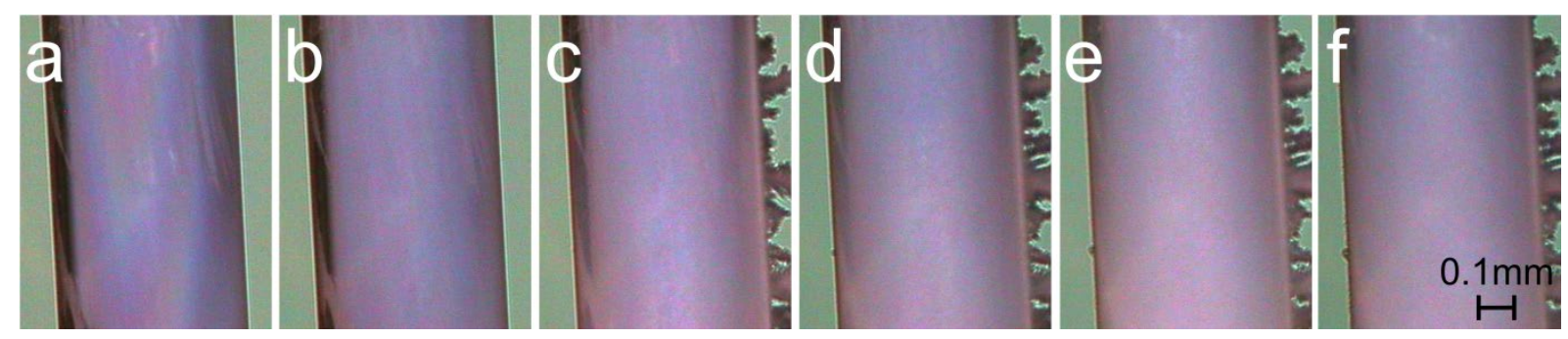

Figure S5. Capillary filled with water:pyrimidine binary mixture (4:1 molar ratio) before and after PXRD experiments, respectively, at $195(a, b), 170(c, d), 140 \mathrm{~K}(e, f)$. Cooling of the sample was carried out using a $3 \mathrm{~K} \cdot \mathrm{min}^{-1}$ rate. Icing of the sample visible in figures $\mathrm{c}-\mathrm{f}$ is due to the high humidity and use of a fast nitrogen flow.
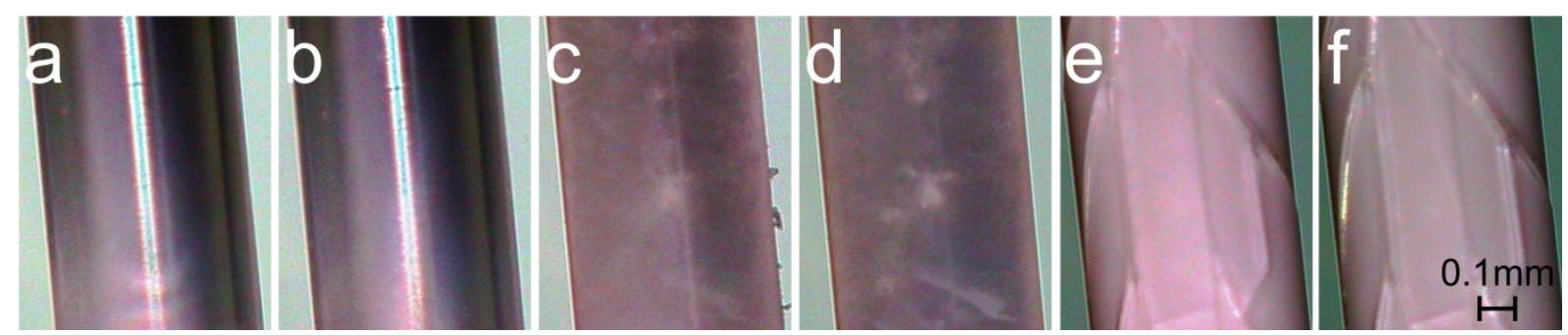

Figure S6. Capillary filled with water:pyrimidine binary mixture (3:1 molar ratio) before and after PXRD experiments, respectively, at 140 (a,b), 200 (c,d), $220 \mathrm{~K}(\mathrm{e}, \mathrm{f})$. Sample was shocked cooled at $140 \mathrm{~K}$ and subsequently heated using $2.5 \mathrm{~K} \cdot \mathrm{min}^{-1}$ rate. 


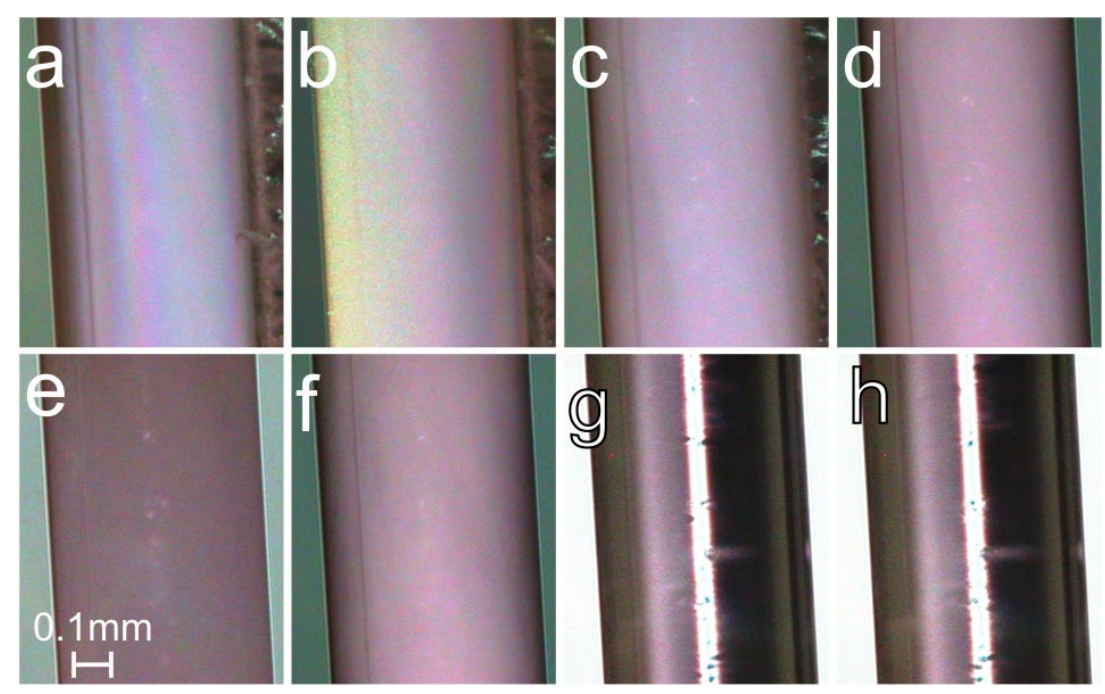

Figure S7. Capillary filled with water:pyrimidine binary mixture (3:1 molar ratio) before and after PXRD experiments, respectively, at 160 (a,b), 215 (c,d), 228 (e,f) and $250 \mathrm{~K}(\mathrm{~g}, \mathrm{~h})$. Sample was shocked cooled at $140 \mathrm{~K}$ and subsequently heated using $2.5 \mathrm{~K} \cdot \mathrm{min}^{-1}$ rate.

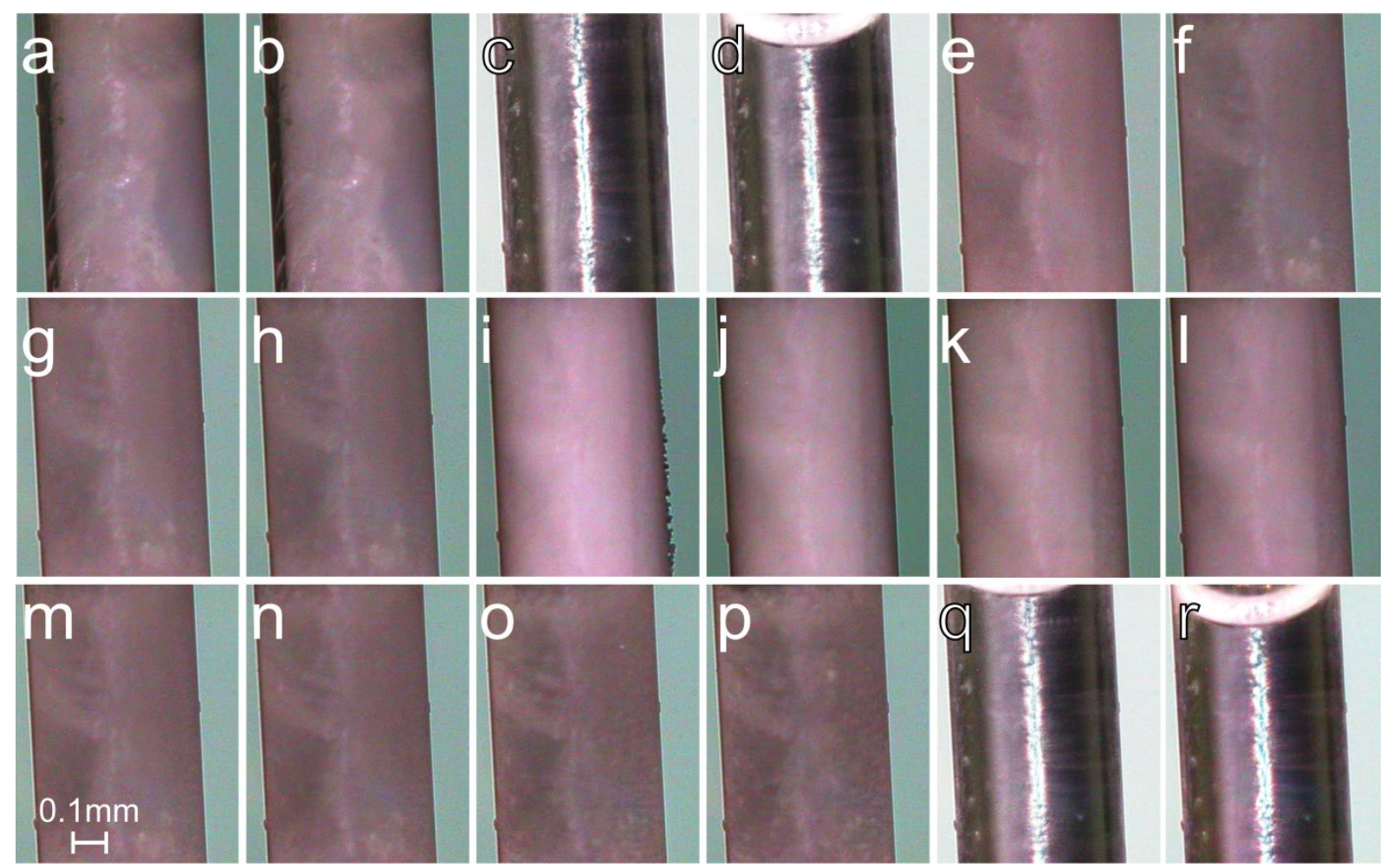

Figure S8. Capillary filled with water:pyrimidine binary mixture (2:3 molar ratio) before and after PXRD experiments, respectively, after shock cooling at 140 (a,b), as well as at 255 (c,d), 245 (e,f), 230 $(\mathrm{g}, \mathrm{h}), 220(\mathrm{l}, \mathrm{j}) \mathrm{K}$, on cooling of the sample using $3 \mathrm{~K} \cdot \mathrm{min}^{-1}$ rate, and at $225(\mathrm{k}, \mathrm{l}), 245(\mathrm{~m}, \mathrm{n}), 255(\mathrm{o}, \mathrm{p})$ and $280 \mathrm{~K}(q, \mathrm{r})$, on heating of the sample using $2.5 \mathrm{~K} \cdot \mathrm{min}^{-1}$ rate. 


\section{Differential Scanning Calorimetry Thermographs}

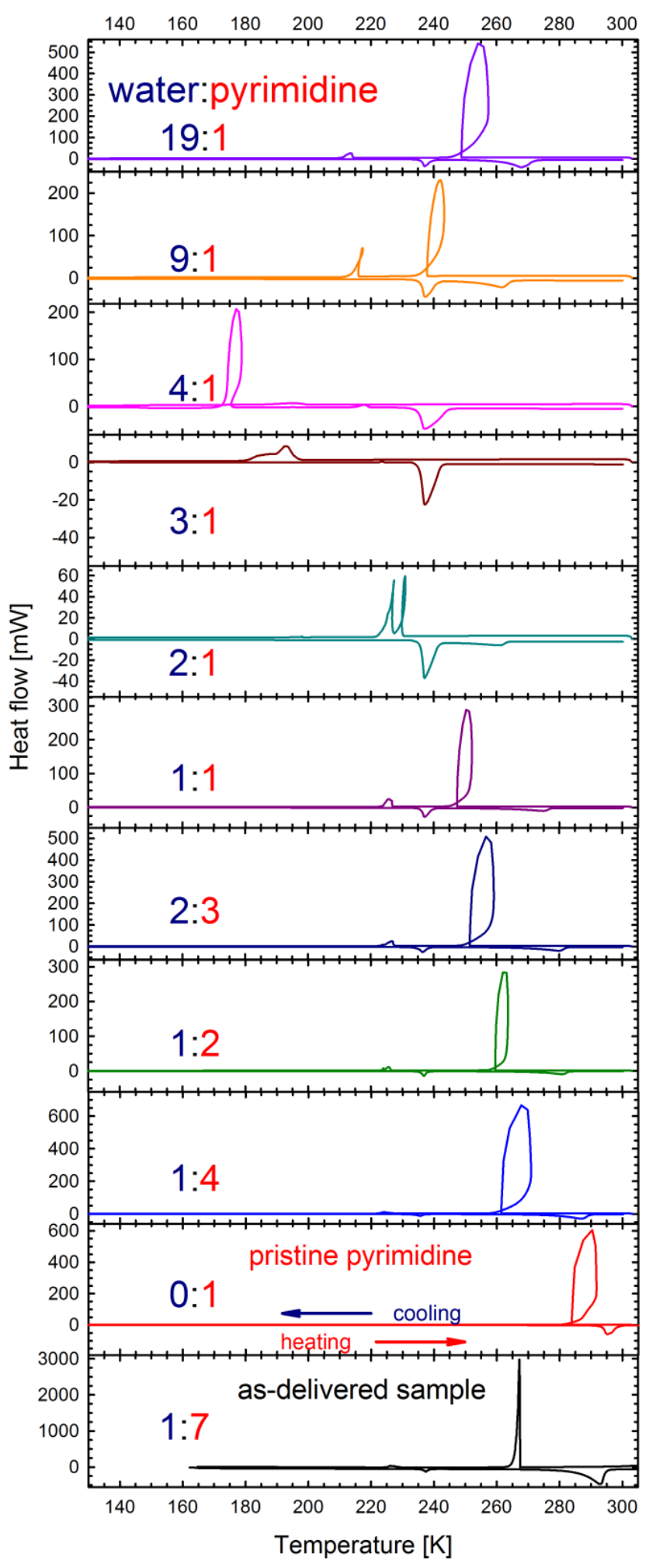

Figure S9. Differential scanning calorimetry (DSC) thermographs for series of pyrimidine and water mixtures, as well as dry pyrimidine shown in the $130-305 \mathrm{~K}$ range and performed with a rate of $10 \mathrm{~K} \cdot \mathrm{min}^{-1}$ (except for asdelivered sample measured with $10 \mathrm{~K} \cdot \mathrm{min}^{-1}$ rate). Arrows indicate the directions of temperature changes. 


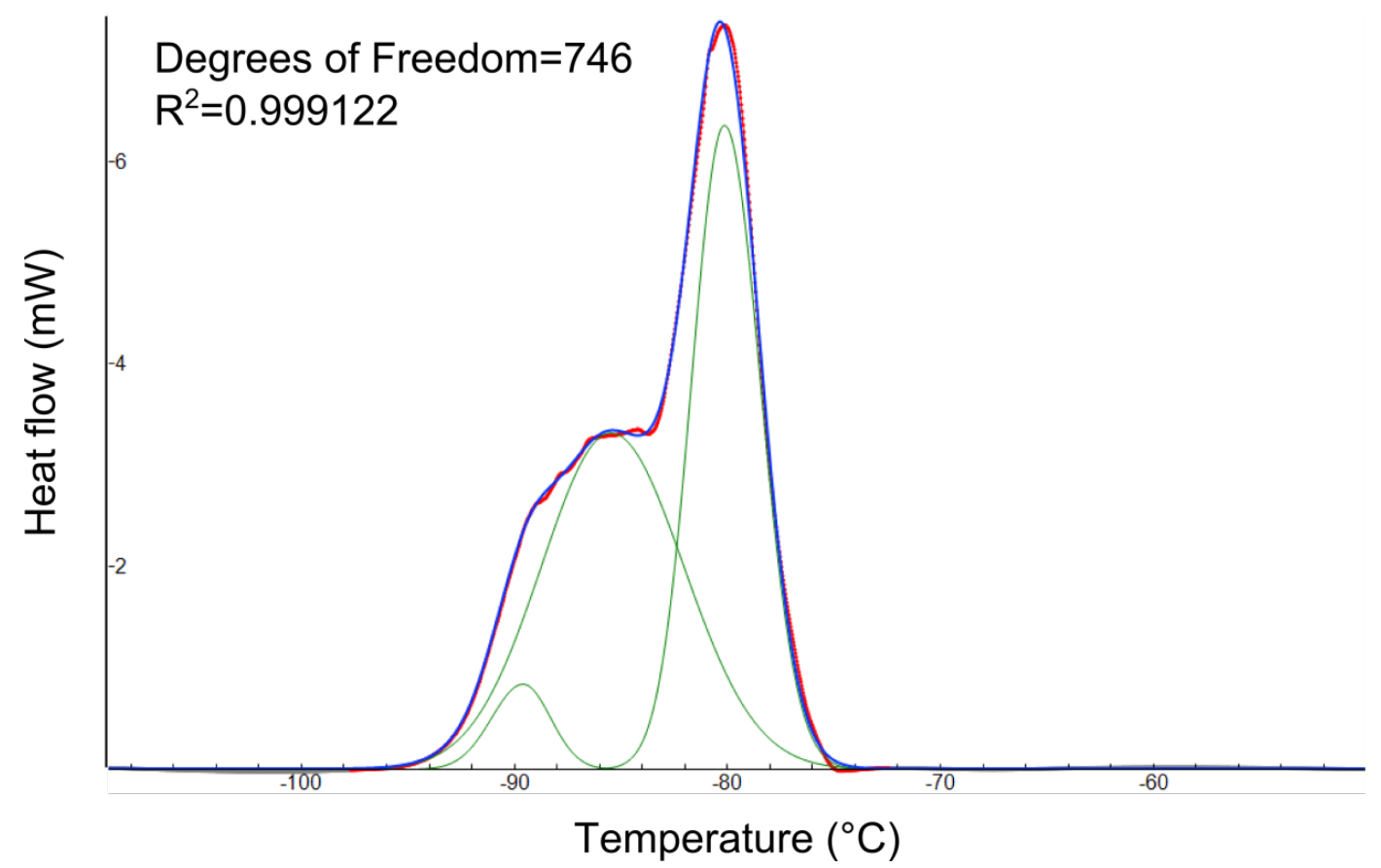

Figure S10. Deconvolution of overlapped peaks (red dotted line) from cooling run in DSC thermograph of water:pyrimidine binary mixture in 3:1 molar ratio. In order to create model function (blue solid line) consistent with experimental data, three Split Gaussian functions (green solid lines) were fitted, after background subtraction, with Fityk program (version 1.3.1) using LevenbergMarquardt algorithm.

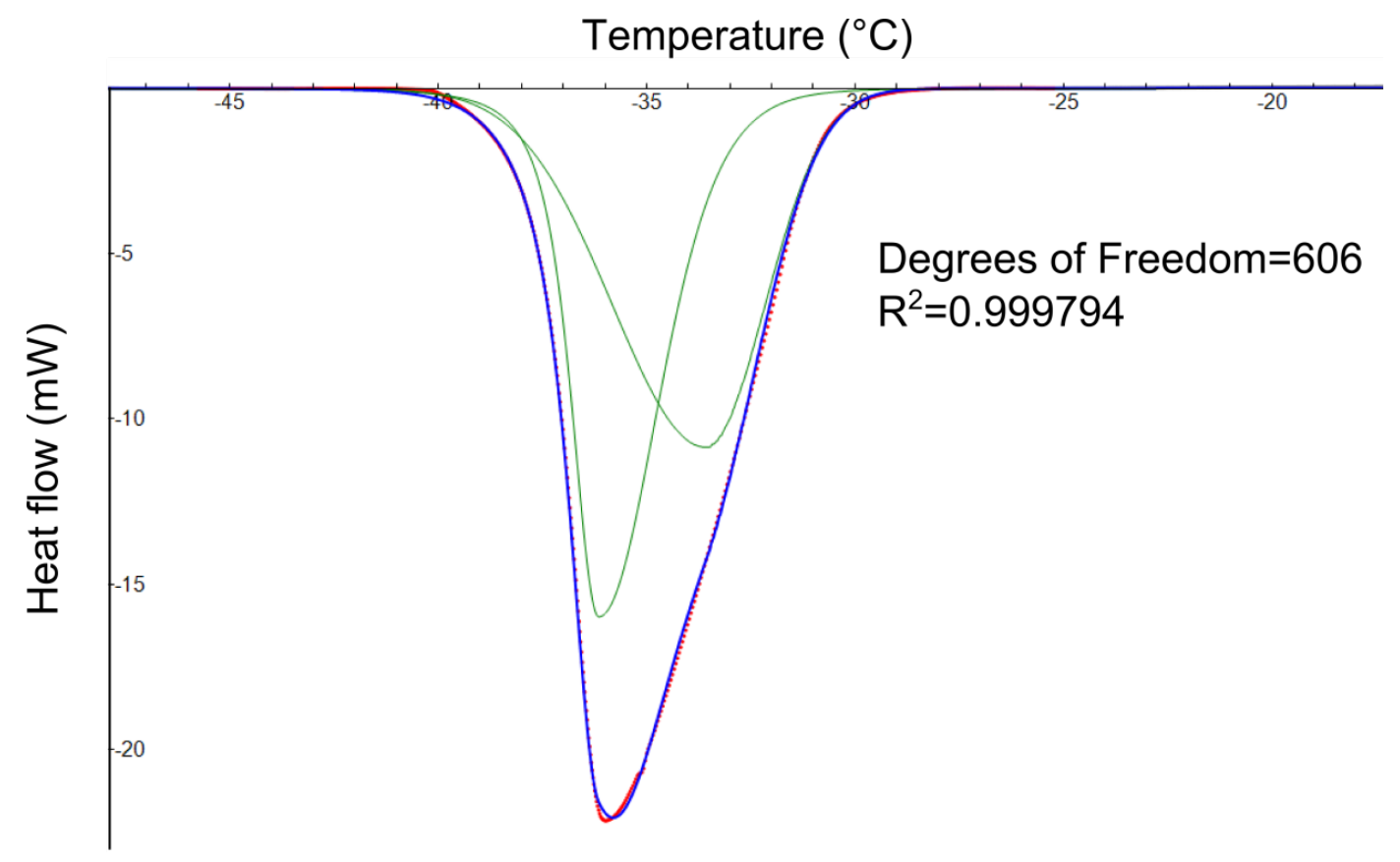

Figure S11. Deconvolution of overlapped peaks (red dotted line) from heating run in DSC thermograph of water:pyrimidine binary mixture in 3:1 molar ratio. In order to create model function (blue solid line) consistent with experimental data, two Split Pearson7 functions (green solid lines) were fitted, after background subtraction, with Fityk program (version 1.3.1) using LevenbergMarquardt algorithm. 


\section{Temperature $\left({ }^{\circ} \mathrm{C}\right)$}

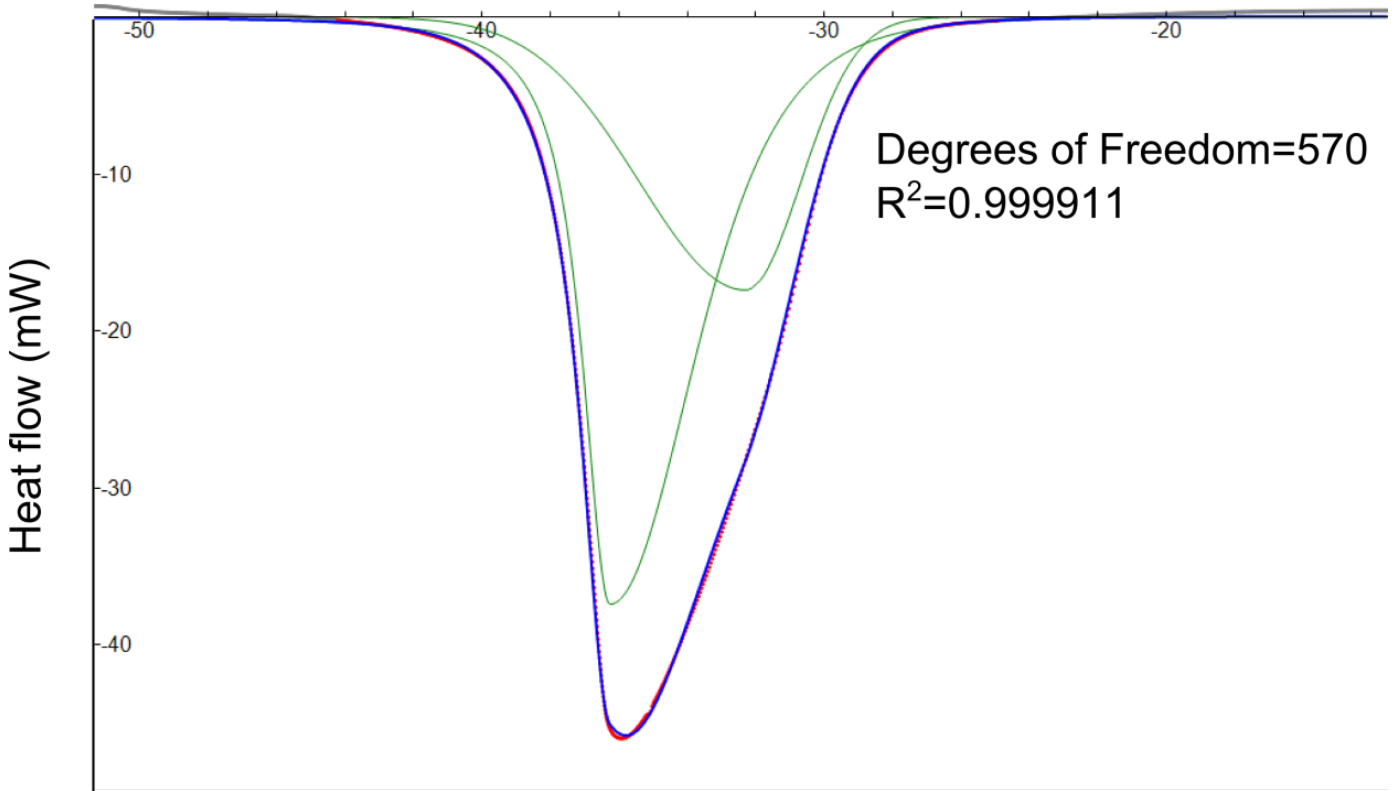

Figure S12. Deconvolution of overlapped peaks (red dotted line) from heating run in DSC thermograph of water:pyrimidine binary mixture in 4:1 molar ratio. In order to create model function (blue solid line) consistent with experimental data, two Split Pearson7 functions (green solid lines) were fitted, after background subtraction, with Fityk program (version 1.3.1) using LevenbergMarquardt algorithm.

Table S1. Crystallization and melting temperatures for water and pyrimidine determined, based on the onset and maximum of peaks, from differential scanning calorimetry (DSC) thermographs (colour coding: red-position of a vitrification slope; green- position of positive peaks present in the heating run of DSC)

\begin{tabular}{|c|c|c|c|c|c|c|c|c|c|c|c|c|c|c|c|}
\hline \multirow{3}{*}{$\begin{array}{l}W: P \\
0: 1\end{array}$} & \multicolumn{7}{|c|}{ Onset } & \multicolumn{8}{|c|}{ Maximum } \\
\hline & \multicolumn{2}{|c|}{ Cooling (K) } & \multicolumn{5}{|c|}{ Heating (K) } & \multicolumn{3}{|c|}{ Cooling (K) } & \multicolumn{5}{|c|}{ Heating (K) } \\
\hline & 283.9 & - & \multicolumn{3}{|c|}{293.6} & \multicolumn{2}{|c|}{ - } & 290.4 & \multicolumn{2}{|r|}{ - } & \multicolumn{3}{|c|}{295.3} & \multicolumn{2}{|c|}{-} \\
\hline $1: 4$ & 261.5 & 228.5 & \multicolumn{3}{|c|}{277.5} & \multicolumn{2}{|c|}{233} & 269.8 & \multicolumn{2}{|r|}{224} & \multicolumn{3}{|c|}{286.6} & \multicolumn{2}{|c|}{235.6} \\
\hline $1: 2$ & 260 & 226.5 & \multicolumn{3}{|c|}{272.0} & \multicolumn{2}{|c|}{235.5} & 263 & \multicolumn{2}{|r|}{225.7} & \multicolumn{3}{|c|}{280.5} & \multicolumn{2}{|c|}{236.8} \\
\hline $2: 3$ & 251.5 & 227.5 & \multicolumn{3}{|c|}{269.0} & \multicolumn{2}{|c|}{234.5} & 256.7 & & 226.5 & & 279.4 & & 236 & \\
\hline $1: 1$ & 246.5 & 227.0 & & 54.5 & & 232 & & 250.3 & & 225.3 & & 274.4 & & 237 & \\
\hline $2: 1$ & 230.5 & 226.5 & & 8.5 & & 235 & & 230.7 & & 227.3 & & 261.1 & & 237 & \\
\hline $3: 1$ & $\begin{array}{l}\stackrel{*}{\circ} \\
\text { ஸ் } \\
\stackrel{\sim}{न}\end{array}$ & $\begin{array}{l}\stackrel{*}{N} \\
\ddot{\infty} \\
\stackrel{\infty}{\sim}\end{array}$ & & & $235.2^{*}$ & & $6^{*}$ & $\begin{array}{l}\stackrel{*}{\circ} \\
\text { m̃ } \\
\text { Oे }\end{array}$ & $\begin{array}{l}\stackrel{*}{\llcorner} \\
\stackrel{+}{\infty} \\
\stackrel{-}{1}\end{array}$ & $\begin{array}{l}\stackrel{*}{+} \\
\infty \\
\infty \\
\sim\end{array}$ & $\begin{array}{l}\stackrel{*}{6} \\
\stackrel{0}{n}\end{array}$ & & $\stackrel{*}{\stackrel{*}{*}}$ & & 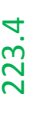 \\
\hline $4: 1$ & 187.0 & 149.4 & $\stackrel{*}{\stackrel{*}{\sim}}$ & $\begin{array}{l}\stackrel{*}{\infty} \\
\stackrel{\dot{\sim}}{N}\end{array}$ & $\underset{\stackrel{\sim}{\sim}}{\stackrel{\sim}{N}}$ & $\begin{array}{l}\circ \\
\stackrel{+}{r}\end{array}$ & 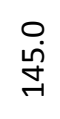 & 184.8 & & 149.4 & $\begin{array}{l}* \\
\infty \\
\dot{0} \\
\stackrel{d}{~}\end{array}$ & $\begin{array}{l}\stackrel{*}{\sigma} \\
\dot{\omega} \\
\stackrel{n}{N}\end{array}$ & $\begin{array}{l}\circ \\
\infty \\
\stackrel{-}{N}\end{array}$ & $\begin{array}{l}\stackrel{0}{0} \\
\stackrel{\infty}{\circ}\end{array}$ & 굼 \\
\hline $9: 1$ & 238.0 & 216.0 & & 55.0 & & 235 & & 241.6 & & 217.0 & & 61.9 & & 237 & \\
\hline 19:1 & 249.0 & 214.5 & & 50.8 & & 235 & & 254.08 & & 213.8 & & 68.0 & & 236 & \\
\hline $\begin{array}{c}\text { As } \\
\text { received } \\
\text { sample }^{4}\end{array}$ & 272.5 & 230 & & 85.0 & & 235 & & 272.5 & & 234.0 & & 92.5 & & 237 & \\
\hline
\end{tabular}




\section{Powder X-Ray Diffraction Patterns}

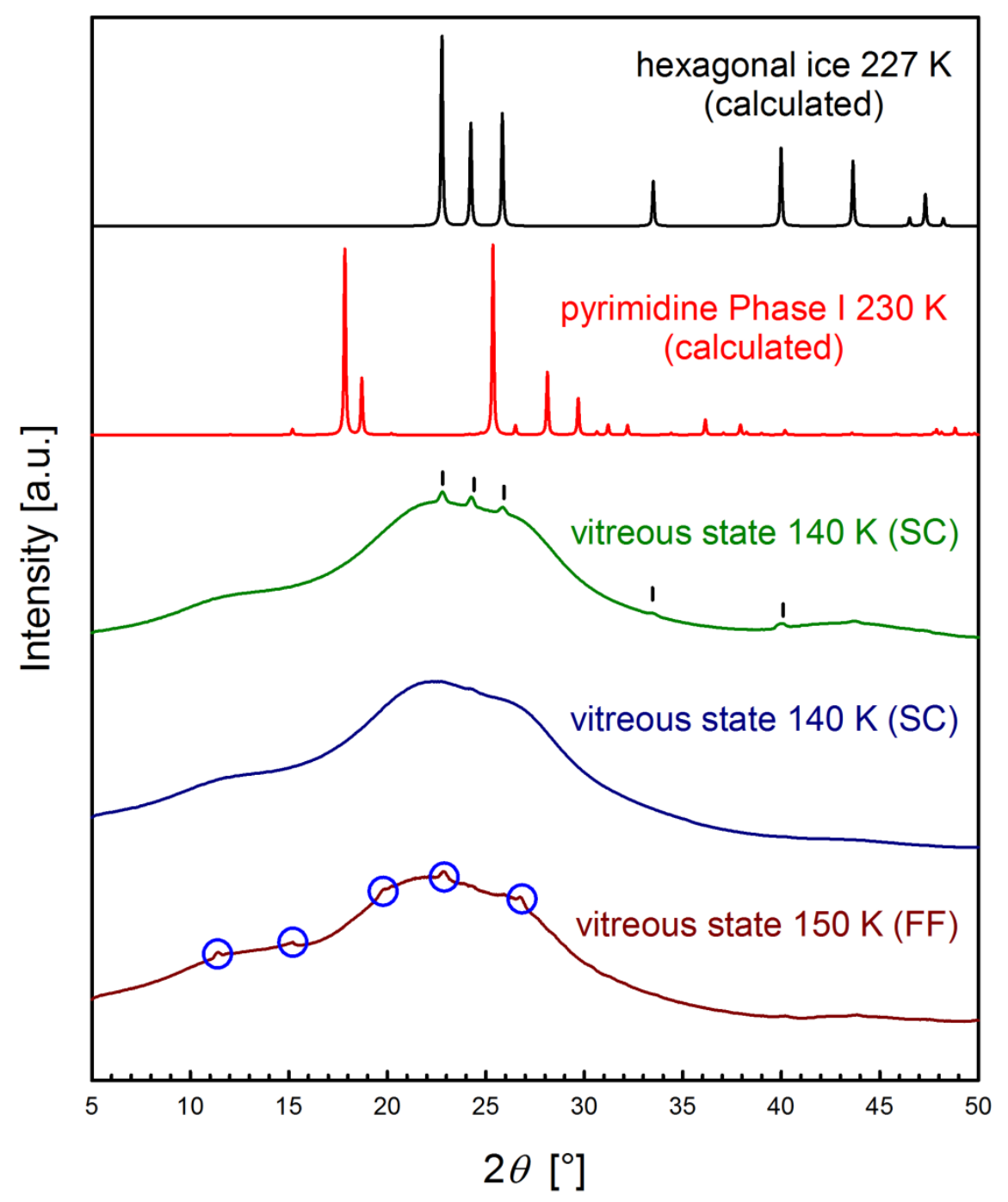

Figure S13. Powder diffractograms of a vitrified water:pyrimidine sample in 4:1 molar ratio measured in situ after $3 \mathrm{~K} \cdot \mathrm{min}^{-1}$ rate (dark red) and shock cooling (blue and green) at 150 and $140 \mathrm{~K}$, respectively. PXRD patterns calculated with program Mercury based on the single-crystal data for pyrimidine phase I (red) and hexagonal ice (black) were included for comparison. Black ticks included above PXRD pattern of vitrified sample at $140 \mathrm{~K}$ (green) mark peaks corresponding to hexagonal ice. Unidentified diffraction peaks, presumably of phase $X$, emerging from the otherwise amorphous PXRD pattern for vitrified sample at $150 \mathrm{~K}$ (dark red), were marked with blue circles. 


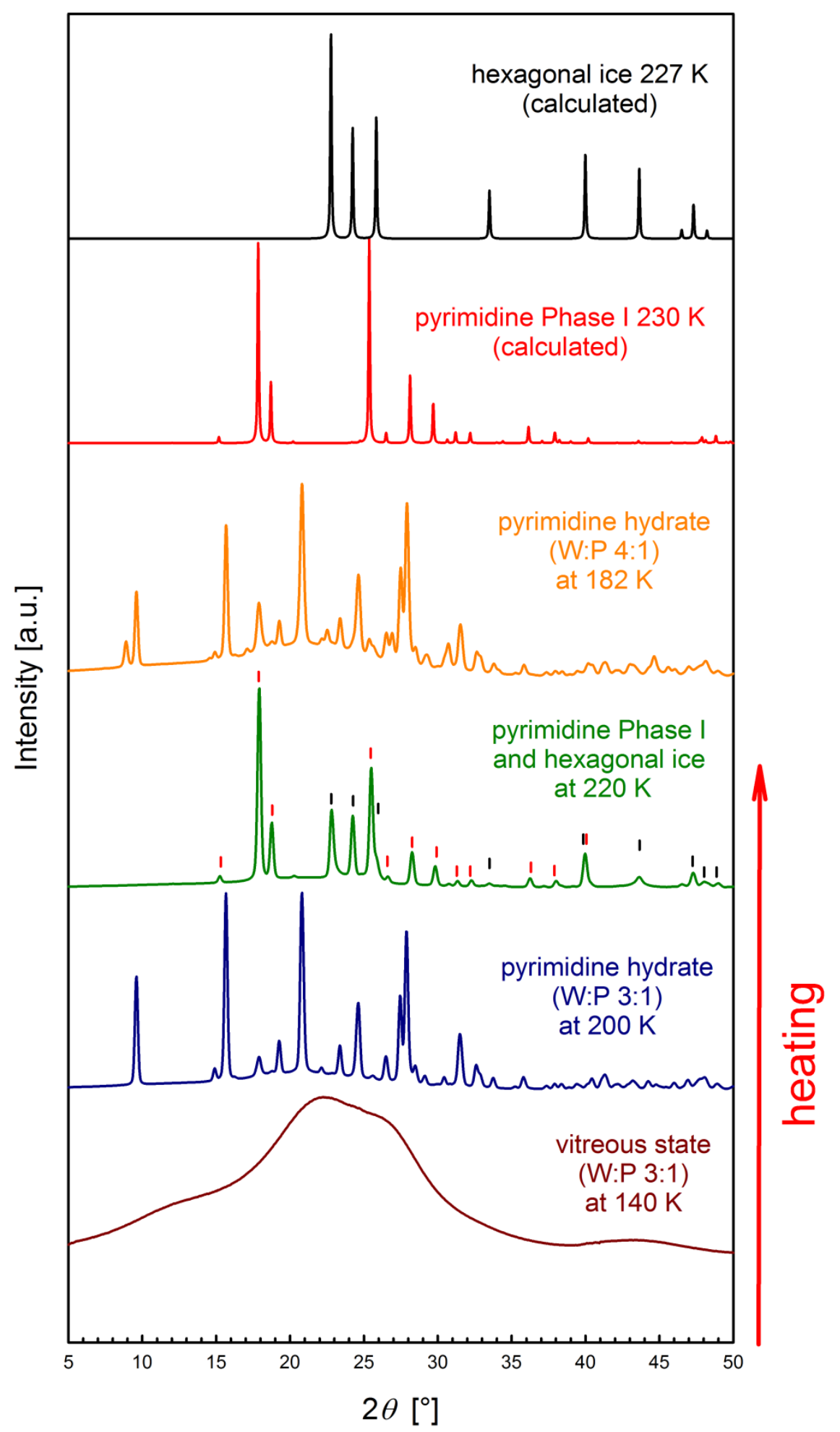

Figure S14. Powder diffractograms of a water:pyrimidine sample in 3:1 molar ratio measured in situ after shock cooling at $140 \mathrm{~K}$ and subsequent heating $\left(2.5 \mathrm{~K} \cdot \mathrm{min}^{-1}\right.$ rate). PXRD patterns calculated with program Mercury based on the single-crystal data for pyrimidine phase I (red) and hexagonal ice (black), as well as experimental PXRD pattern of powder sample obtained after heating vitrified water:pyrimidine mixture in 4:1 molar ratio (orange), were included for comparison. Red and black ticks included above PXRD pattern for sample measured at $220 \mathrm{~K}$ (dark green) mark peaks corresponding to pyrimidine phase I and hexagonal ice, respectively. 


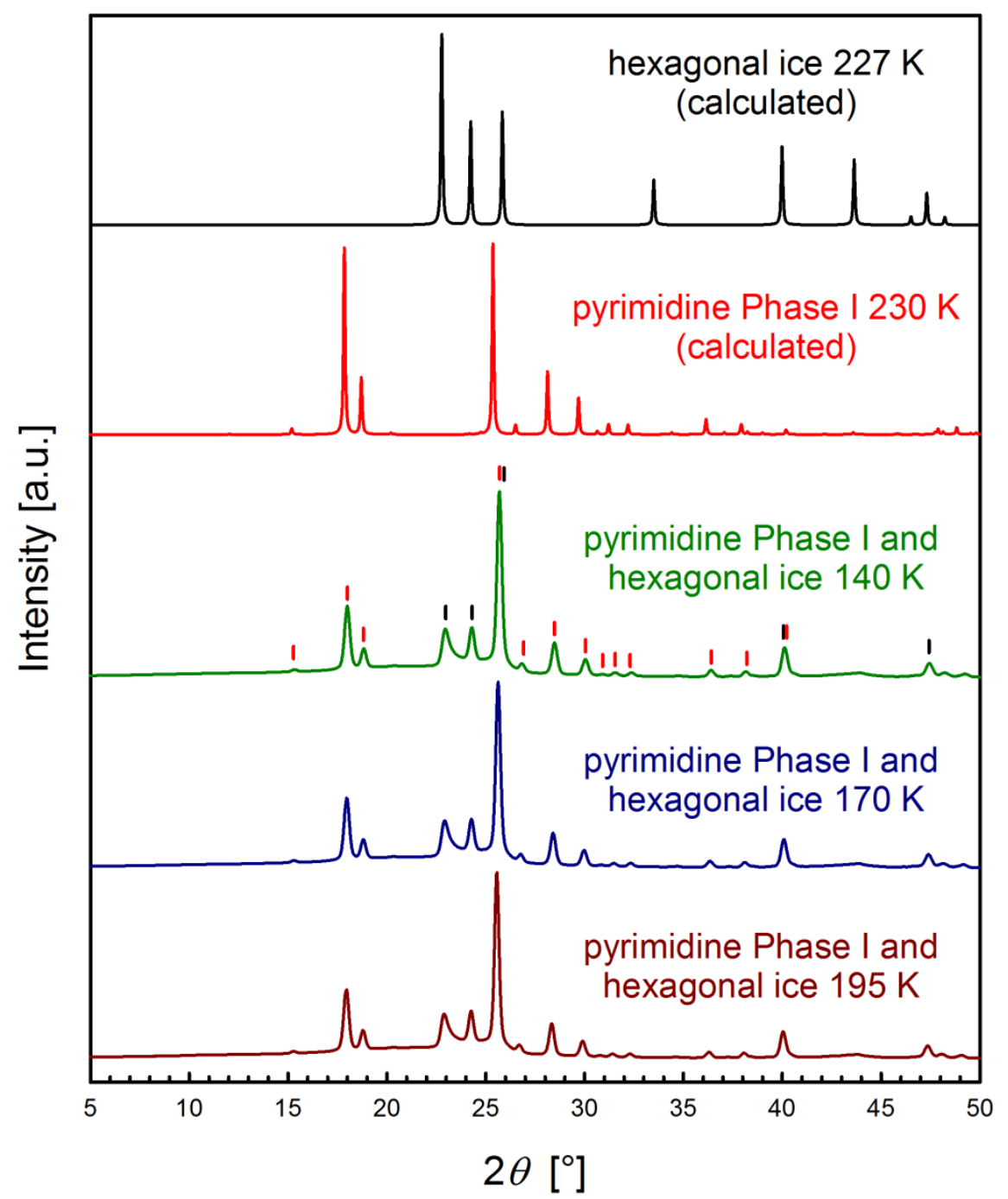

Figure S15. Powder diffractograms of a water:pyrimidine sample in 4:1 molar ratio measured during cooling of the sample at $3 \mathrm{~K} \cdot \mathrm{min}^{-1}$ rate at 195, 170 and $140 \mathrm{~K}$. PXRD patterns calculated with program Mercury based on the single-crystal data for pyrimidine phase I (red) and hexagonal ice (black) were included for comparison. Red and black ticks included above PXRD pattern for sample measured at $140 \mathrm{~K}$ (dark green) mark peaks corresponding to pyrimidine phase I and hexagonal ice, respectively. 


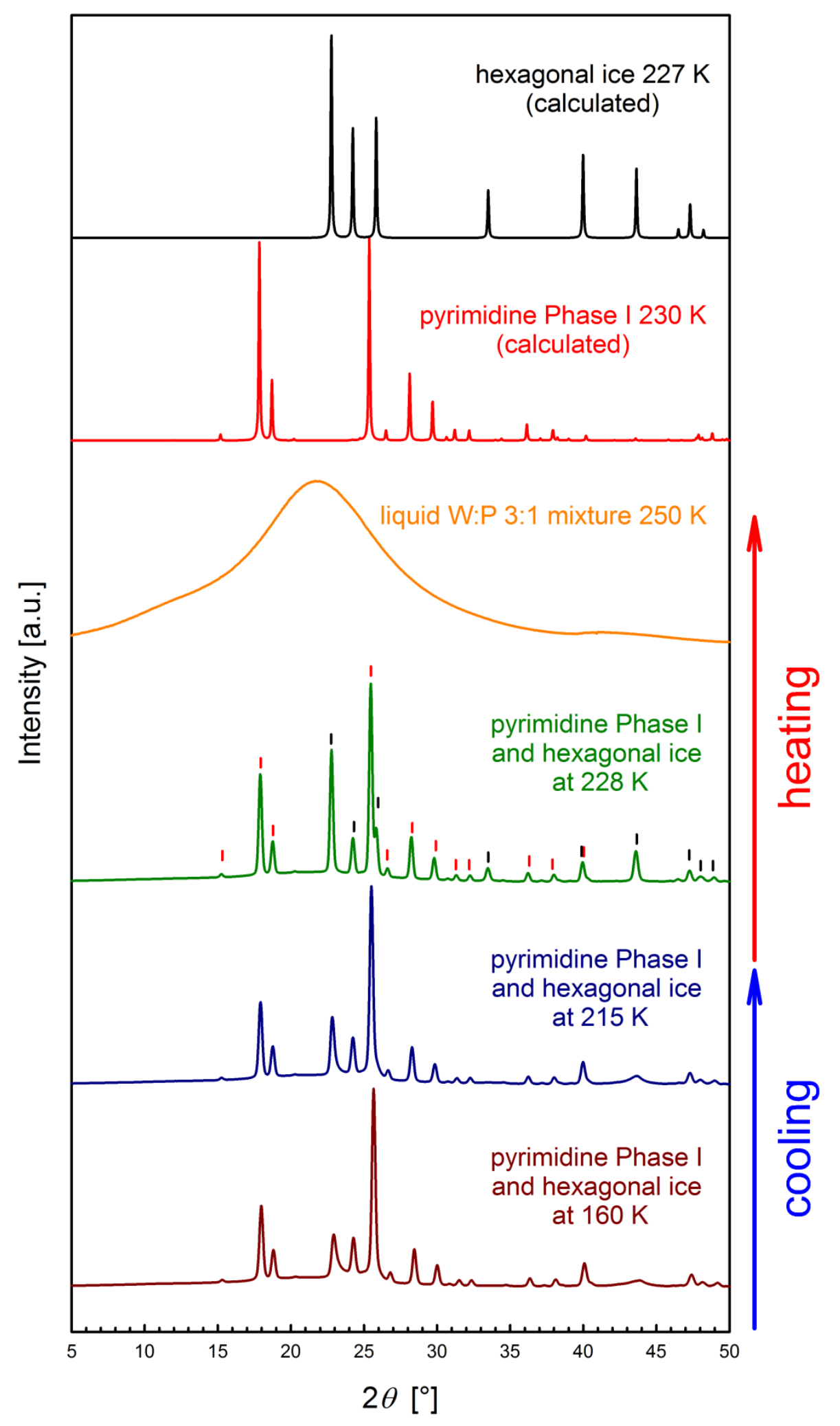

Figure S16. Powder diffractograms of a water:pyrimidine sample in 3:1 molar ratio measured in situ during cooling at $3 \mathrm{~K} \cdot \mathrm{min}^{-1}$ rate (blue arrow) and heating $\left(2.5 \mathrm{~K} \cdot \mathrm{min}^{-1}\right.$ rate; red arrow). PXRD patterns calculated with program Mercury based on the single-crystal data for pyrimidine phase I (red) and hexagonal ice (black) were included for comparison. Red and black ticks included above PXRD pattern for sample measured at $228 \mathrm{~K}$ during heating run (dark green) mark peaks corresponding to pyrimidine phase I and hexagonal ice, respectively. 


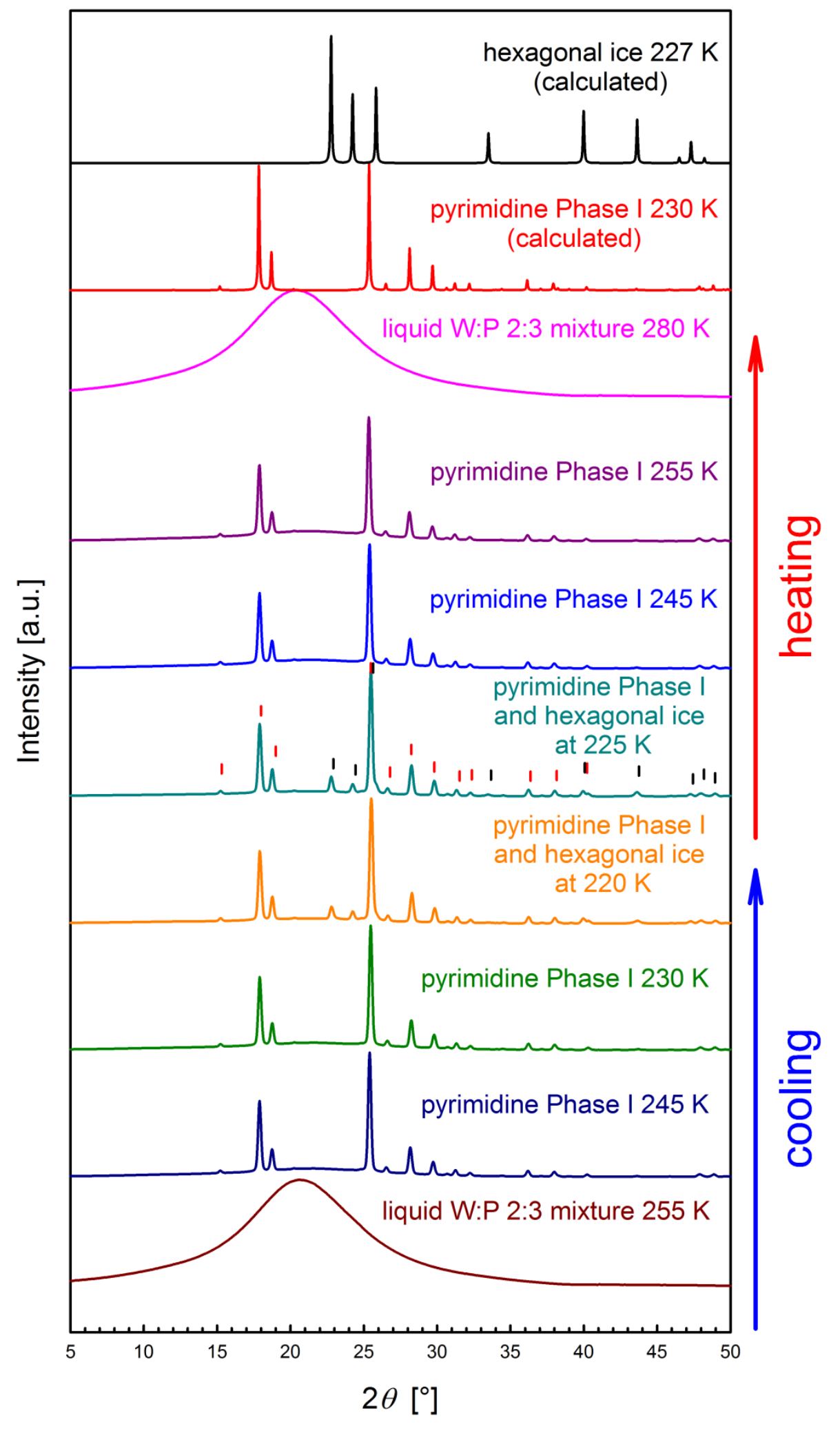

Figure S17. Powder diffractograms of a water:pyrimidine sample in 2:3 molar ratio measured in situ during cooling at $3 \mathrm{~K} \cdot \mathrm{min}^{-1}$ rate (blue arrow) and heating $\left(2.5 \mathrm{~K} \cdot \mathrm{min}^{-1}\right.$ rate; red arrow). PXRD patterns calculated with program Mercury based on the single-crystal data for pyrimidine phase I (red) and hexagonal ice (black) were included for comparison. Red and black ticks included above PXRD pattern for sample measured at $255 \mathrm{~K}$ during heating run (dark cyan) mark peaks corresponding to pyrimidine phase I and hexagonal ice, respectively. 


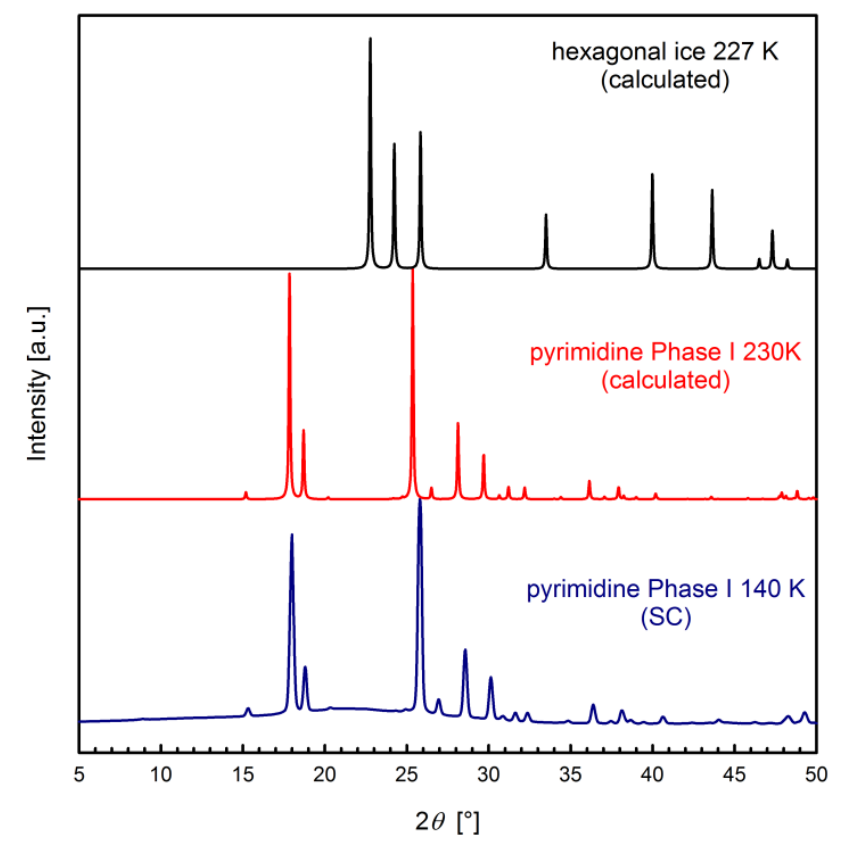

Figure S18. Powder diffractograms of a water:pyrimidine sample in 2:3 molar ratio measured after shock cooling at $140 \mathrm{~K}$ (blue). PXRD patterns calculated with program Mercury based on the singlecrystal data for pyrimidine phase I (red) and hexagonal ice (black) were included for comparison.

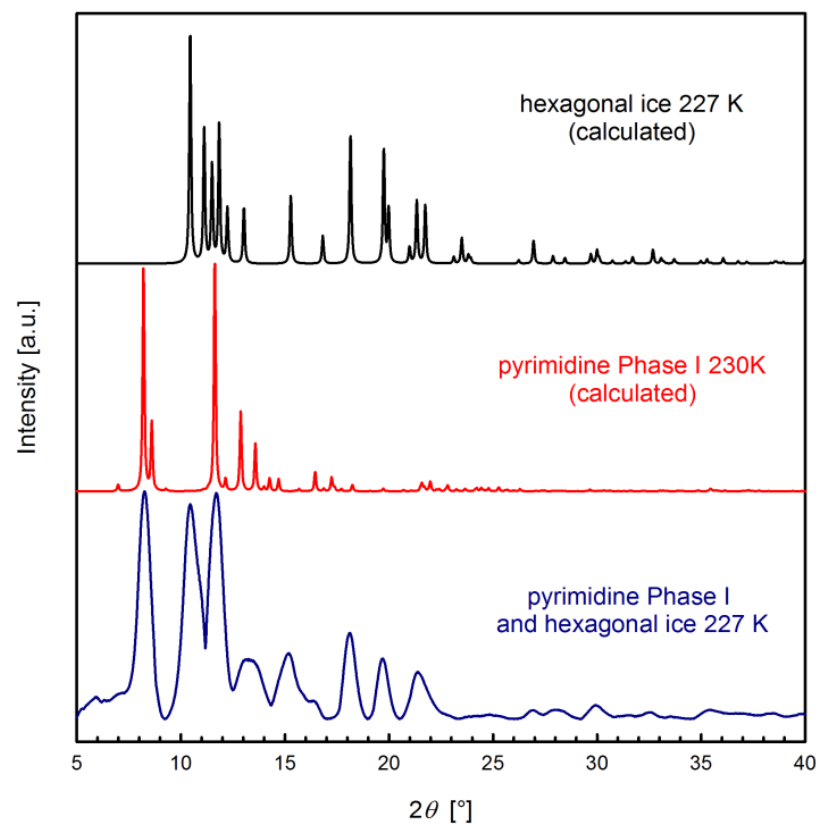

Figure S19. Powder diffractograms calculated based on a single crystal structures of pyrimidine phase I at $230 \mathrm{~K}$ (red), hexagonal ice at $227 \mathrm{~K}$ (black), as well as experimental diffractogram extracted from single-crystal experiment of crystalline sample obtained in situ in a capillary (blue). Since, single-crystal experiment was performed using $\mathrm{MoK}_{\alpha}$ radiation, for calculation of pyrimidine phase I and hexagonal ice PXRD patterns $\lambda=0.71073 \AA$ Å was used. 
The quality of the PXRD data did not allowed accurate determination of the lattice constants, crystal symmetry of the pyrimidine hydrate and its crystal structure. On the other hand, insitu growth of a single crystal suitable for SCXRD experiment, requiring repeated slow heating and cooling of the sample, was not possible due to the kinetic stability of the hydrate (as shown in PXRD experiments, even slight alteration in the cooling rate leads to separate crystallisation of pyrimidine and water). In fact, during in-situ SCXRD study of water:pyrimidine binary mixture in 3:1 molar ratio, cooling and heating of the sample led to formation of few crystallites, however, thorough analysis of diffraction data (Figure S19) revealed those crystallites to be hexagonal ice $I_{h}$, surrounded by powder pyrimidine phase $I$. 